\title{
miR-Q: a novel quantitative RT-PCR approach for the expression profiling of small RNA molecules such as miRNAs in a complex sample
}

\author{
Soroush Sharbati-Tehrani*, Barbara Kutz-Lohroff, Ramona Bergbauer, \\ Jutta Scholven and Ralf Einspanier
}

Address: Institute of Veterinary-Biochemistry, Freie Universität Berlin, Oertzenweg 19 b, 14163 Berlin, Germany

Email: Soroush Sharbati-Tehrani* - sharbati@zedat.fu-berlin.de; Barbara Kutz-Lohroff - kutz.barbara@vetmed.fu-berlin.de; Ramona Bergbauer - bergbauer.ramona@vetmed.fu-berlin.de; Jutta Scholven - scholven.jutta@vetmed.fu-berlin.de;

Ralf Einspanier - einspani@zedat.fu-berlin.de

* Corresponding author

Published: 10 April 2008

BMC Molecular Biology 2008, 9:34 doi:10.1186/1471-2199-9-34

This article is available from: http://www.biomedcentral.com/I47I-2/99/9/34

(C) 2008 Sharbati-Tehrani et al; licensee BioMed Central Ltd.

This is an Open Access article distributed under the terms of the Creative Commons Attribution License (http://creativecommons.org/licenses/by/2.0), which permits unrestricted use, distribution, and reproduction in any medium, provided the original work is properly cited.
Received: 20 August 2007

Accepted: 10 April 2008

\begin{abstract}
Background: MicroRNAs (miRNAs) are small endogenous non-coding interfering RNA molecules regarded as major regulators in eukaryotic gene expression. Different methods are employed for miRNA expression profiling. For a better understanding of their role in essential biological processes, convenient methods for differential miRNA expression analysis are required.

Results: Here, we present the miR-Q assay as a highly sensitive quantitative reverse transcription PCR (qRT-PCR) for expression analysis of small RNAs such as miRNA molecules. It shows a high dynamic range of 6 to 8 orders of magnitude comprising a sensitivity of up to $0.2 \mathrm{fM}$ miRNA, which corresponds to single copies per cell. There is nearly no cross reaction among closely-related miRNA family members, which points to the high specificity of the assays. Using this approach, we quantified the expression of let-7b in different human cell lines as well as miR-|45 and miR-2I expression in porcine intestinal samples.
\end{abstract}

Conclusion: miR-Q is a cost-effective and highly specific approach, which neither requires the use of fluorochromic probes, nor Locked Nucleic Acid (LNA)-modified oligonucleotides. Moreover, it provides a remarkable increase in specificity and simplified detection of small RNAs.

\section{Background}

RNA interference (RNAi) is an evolutionarily-conserved process that modulates gene expression. Recently, miRNA molecules have been described as playing a major role among non-coding small interfering RNAs. MiRNAs represent an abundant and highly conserved family of endogenous single-stranded small RNA molecules of approximately 20-25 nucleotides in length. The high evolutionary conservation of miRNAs from distantly related species indicates their role in various crucial biological processes. Recent studies have demonstrated that miRNAs act as major regulators of developmental timing, cellular differentiation, apoptosis, and signalling pathways [1]. In plants, RNAi has also been described as a phenomenon called post-transcriptional gene silencing [2]. Within this context, miRNAs posses similar functions in plants such as organ development, signal transduction, and response to environmental stress [3]. 
Animal miRNAs derive from long endogenous primary transcripts with a local stem-loop structure, which is successively cleaved by cellular RNases to build the mature miRNA [4]. One of the strands interacts with the RNAinduced silencing complex (RISC) and binds to a target site, which is located in the 3' UTR of the related mRNA. Most animal miRNAs bind to their targets with incomplete complementarity [1], while their regulatory impact is mainly based on the reduction of translation efficiency, rather than on enhanced mRNA degradation [5].

Due to the enormous regulative importance of miRNAs, research on miRNA expression analysis has recently increased. Although miRNAs represent a relatively abundant class of transcripts, their expression levels vary greatly among species and tissues [6]. Various methods are employed for detection and differential expression analysis of miRNAs in biological samples. Initial miRNA expression studies were performed by means of Northern blot analysis [7]. This method is well-established but is very laborious and highly limited, regarding sample throughputs. Recently, Microarrays have been used for genome-wide miRNA profiling based on different processing chemistries [8-10]. Microarrays provide a robust platform for fast screening and comparative expression analysis of miRNAs, but are limited, regarding accurate quantification of gene expression and need high quantities of RNA. Thus, less abundant miRNAs often escape detection by technologies such as cloning, Northern blot analysis and Microarray. A single-molecule method for quantification of miRNA expression was introduced by Neely et al. [11]. Although this technique represents a modern alternative, it has a detection limit of $500 \mathrm{fM}$. Additionally, the method is utilised by a costintensive device, which may be unaffordable for many research groups.

A highly convenient and reliable method for differential gene expression analysis is considered to be qRT-PCR [12], which exhibits high sensitivity and target specificity. It is 1000-fold more sensitive than methods that are based on hybridisation [13] and can even detect a few target copies [14]. However, the small size of miRNAs requires substantial modification of this method because ordinary PCR primers are usually the same size as the small RNA molecules being analysed. The first miRNA real-time PCR approach was based on detection and quantification of miRNA precursors $[15,16]$. However, other studies have shown that the cellular steady-state level of miRNA precursors does not correspond to cellular concentrations of mature miRNAs $[17,18]$. Chen and colleagues [19] have developed a quantitative stem-loop RT-PCR for detection of mature miRNAs that is based on TaqMan assays. Their assay displays high sensitivity and dynamic range and allows for discrimination between members of miRNA families such as let-7. This assay and a few others have recently become commercialised and are rather costly. Raymond et al. [18] have designed a SYBR Green real-time RT-PCR for detection of mature miRNA molecules using LNA-modified primers. Most of their developed assays are described as being sensitive to femtomolar concentrations. However, the performance and sensitivity of $70 \%$ of the analysed assays strictly depend on the use of LNAmodified primers, which increases the costs of this approach.

Due to the rising general interest in miRNA expression and their regulative impact on important biological processes, more sensitive and competitive alternatives applications are in demand. On this account, we have developed a new cost-effective, highly sensitive, and reliable qRTPCR for quantification of small RNA molecules such as miRNAs. The method called miR-Q is based on primer extension, followed by a novel quantitative PCR (qPCR) approach that is carried out using three DNA-oligonucleotides. The assay exhibits high sensitivity, linearity, and discriminative power without the use of complex fluorochromic probes or LNA-modified oligonucleotides.

\section{Results \\ General assay design}

The novel miR-Q approach has been introduced for detection, quantification, and differential expression profiling of small RNA molecules, in particular miRNAs, in a complex sample. During the first step, miRNA molecules are converted into cDNA and simultaneously elongated by reverse transcription using a miRNA-specific oligonucleotide with 5 ' overhang (RT6-miR- $x, x$ indicates one of the ten particular miRNAs). Subsequently, cDNA molecules are amplified and quantified by means of a novel qPCR approach based on utilising three DNA-oligonucleotides at different concentrations (Figure 1). Primarily, a DNAoligonucleotide molecule (RTG-miR-x) is used for reverse transcription, which comprises two main sequence portions. The terminal six bases at the 3' end of RT6-miR- $x$ are miRNA-specific and hybridise to the template RNA molecule of interest. This oligonucleotide molecule also comprises a second sequence portion, enabling the binding of a universal primer (MP-fw) to prime the exponential DNA amplification. For subsequent qPCR analysis, another oligonucleotide molecule (short-miR-x-rev) is employed comprising a miRNA-specific sequence portion at its $3^{\prime}$ end. Therefore, short-miR- $x$-rev can hybridise to the cDNA molecule (complementary to the target miRNA) generated after the reverse transcriptase reaction. In addition, the 5 ' overhang provides a terminal binding sequence for another universal primer (MP-rev). Consequently, two 5' overhangs are introduced to convert and elongate the small RNA molecule. The final exponential amplification is accomplished by means of universal primers (MP-fw 


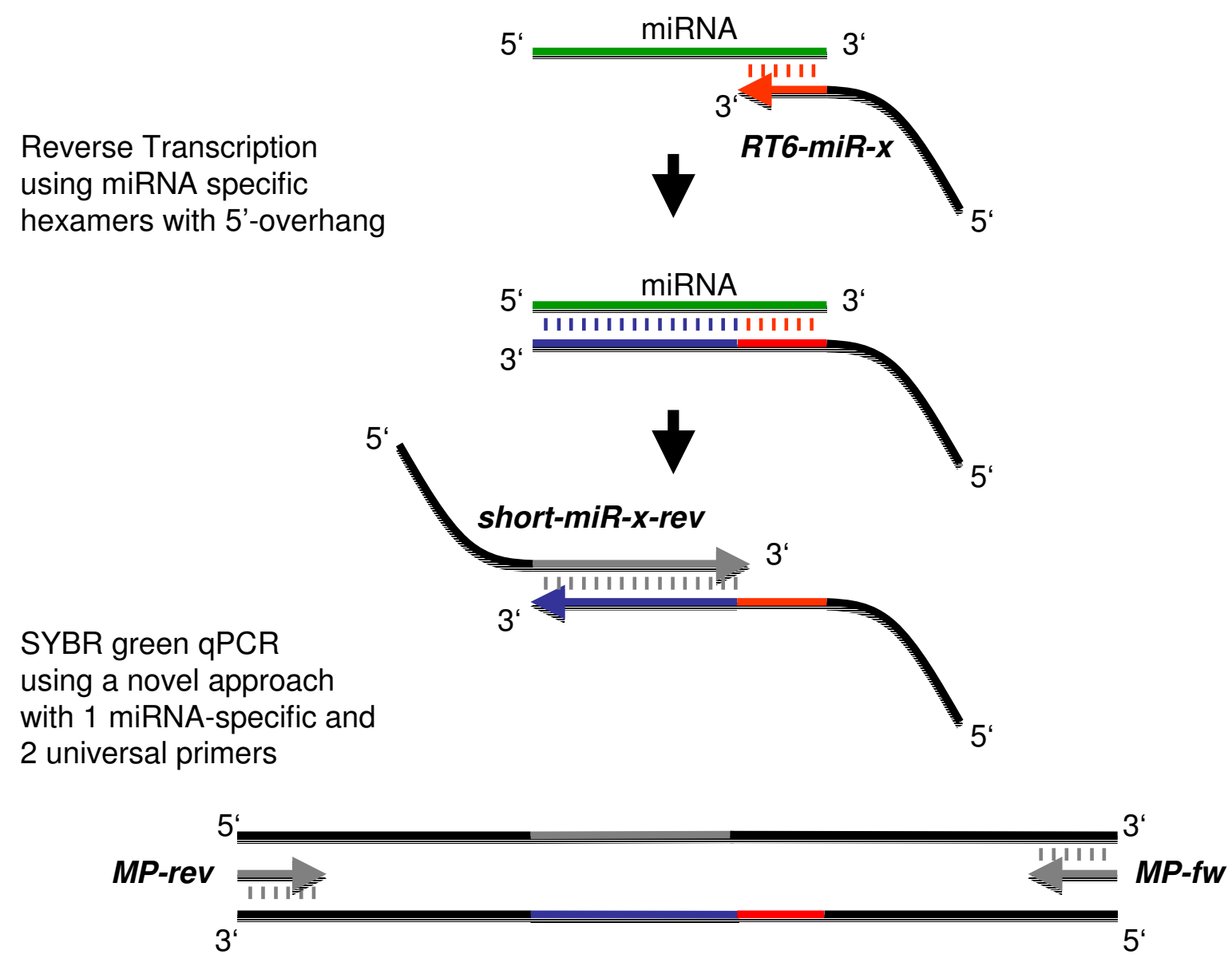

Figure I

Schematic description of assay design. The miRNA is first converted and simultaneously elongated into a cDNA molecule using a miRNA-specific oligonucleotide with 5' overhang (RT6-miR-x) and six complementary bases (red). Detection and amplification of the relating CDNA are employed, using a novel PCR approach with three different oligonucleotides at different concentrations within the same assay. The cDNA sequence (blue) is first detected and elongated by a specific oligonucleotide with 5 ' overhang (short-miR-x-rev). Exponential amplification is then performed using two terminal universal primers (MP-fw \&MP-rev).

and MP-rev), which hybridise to terminal binding sites of the overhangs. These universal primers are not assay-specific and are therefore employed independently of various analysed miRNA molecules. The universal overhang sequences of the reverse primers as well as RT primers have been deduced from mycobacterial genome, finally being optimised for negligible complementarities and dimer formation. The mentioned sequence parts were used to perform blast searches using the Wublastn option of miRBase, Release 9.2 [20]. These universal overhang sequences show no similarity with any known miRNA using an Evalue cutoff $=20$. Even at higher Evalue cutoffs (< 40) only three miRNA molecules show marginal homology to the conserved regions (ebv-miR-BART5, rlcv-miR-rL1-8, and hsa-miR-618).
The final detection and quantification of template miRNA molecules are performed by real-time acquisition of the SYBR Green fluorescence, utilising a calibration curve.

\section{Assay validation, sensitivity, and dynamic range}

Initial assays were performed with miRNA-specific oligonucleotides possessing an overlap of 6 bases with the RT6$m i R-x$, which was used for the initial primer extension reaction to convert and elongate the miRNA molecule in cDNA. Although PCR reactions were performed under stringent conditions, the application of oligonucleotides with 6 overlapping bases produced high background from 30 cycles onwards. Hereafter, we evaluated the use of short-miR-x-rev molecules, which featured basically no or, at most, 3 overlapping bases. The use of shortened miRNA-specific reverse oligonucleotides resulted in a 
higher sensitivity of all assays and a loss of background over 40 cycles.

The dynamic range and sensitivity of all ten miR-Q assays were first proven by performing RT reactions, using the particular synthetic miRNA molecules spiked into $50 \mathrm{ng}$ bacterial total RNA, representing a complex RNA background. Primarily, the assay-specific $\mathrm{T}_{\text {anopt }}$ was evaluated by performing a conventional gradient PCR (annealing temperature gradient: $53-65^{\circ} \mathrm{C}$ ), using an RT reaction prepared with $10 \mathrm{pM}$ synthetic miRNA, with each of the ten containing $50 \mathrm{ng}$ bacterial total RNA as a template. The resulting specific $T_{\text {anopt }}$ of every assay is indicated in Table 1.

Certain amounts of synthetic miRNAs $(10 \mathrm{nM}-1 \mathrm{fM}$ in RT reaction) were applied in order to analyse the dynamic range of the approach. The linearity and sensitivity of the approach were first evaluated using synthetic miR-145, with bacterial total RNA present. The miR-145 assay exhibited excellent linearity over 8 orders of magnitude, detecting as low as $0.2 \mathrm{fM}$ synthetic miR-145 (Figure 2A). The assay exhibited high specificity and sensitivity for miR-145, showing no background signal over 40 cycles either in the non-spiked bacterial total RNA control or in the no template control (Figure 2B). Furthermore, nine distinct miRNA assays were designed and evaluated in the same way using synthetic miRNA molecules and bacterial total RNA as complex background. All of the ten assays showed linearities between the log of miRNA concentration and threshold cycle $(\mathrm{Ct})$ values over more than 6 orders of magnitude. All of the studied assays comprised a high sensitivity showing a minimum detection level of at least $20 \mathrm{fM}$ synthetic miRNA, while most of the assays offered a sensitivity of $2 \mathrm{fM}$. As indicated in Figure 3, most of the validated assays (miR-200c, miR-16, let-7a, let-7b,

Table I: Oligonucleotides used in this study. The assay-specific annealing temperatures are given in the bottom right column. Differing bases among members of the let-7 family are indicated in red. Binding sequences for universal primers are underlined and the miRNA specific sequences are indicated in bold.

\begin{tabular}{|c|c|c|}
\hline $\begin{array}{l}\text { Synthetic miRNA molecules and DNA- } \\
\text { oligonucleotides for RT and qPCR }\end{array}$ & Sequence (5' to $\left.3^{\prime}\right)$ & $\mathrm{T}_{\text {anopt }}$ of miR-Q assays $\left[{ }^{\circ} \mathrm{C}\right]$ \\
\hline let-7a & uga ggu agu agg uug uau agu $u$ & \\
\hline let-7b & uga ggu agu agg uug ugu ggu u & \\
\hline let-7c & uga ggu agu agg uug uau ggu u & \\
\hline$m i R-16$ & uag cag cac gua aau auu ggc $g$ & \\
\hline $\operatorname{miR}-2 I$ & uag cuu auc aga cug aug uug a & \\
\hline $\operatorname{miR}-23 b$ & auc aca uug cca ggg auu acc & \\
\hline $\operatorname{miR}-27 a$ & uuc aca gug gcu aag uuc cgc & \\
\hline $\operatorname{miR}-14 I$ & uaa cac ugu cug gua aag aug $g$ & \\
\hline miR-I 45 & guc cag uuu ucc cag gaa ucc cuu & \\
\hline miR-200c & uaa uac ugc cgg gua aug aug $g$ & \\
\hline RT6-let-7a & tgt cag gca acc gta ttc acc gtg agt ggt aac tat & \\
\hline RT6-let-7b & tgt cag gca acc gta ttc acc gtg agt ggt aac cac & \\
\hline RT6-let-7c & tgt cag gca acc gta ttc acc gtg agt ggt aac cat & \\
\hline RT6- miR-16 & tgt cag gca acc gta ttc acc gtg agt ggt cgc caa & \\
\hline RT6- miR-2I & tgt cag gca acc gta ttc acc gtg agt ggt tca aca & \\
\hline RT6- miR-23b & tgt cag gca acc gta ttc acc gtg agt gct ggt aat & \\
\hline RT6- miR-27a & tgt cag gca acc gta ttc acc gtg agt ggt gcg gaa & \\
\hline RT6- miR-I4I & tgt cag gca acc gta ttc acc gtg agt ggt cca tct & \\
\hline RT6- miR- 145 & tgt cag gca acc gta ttc acc gtg agt ggt aag gga & \\
\hline RT6- miR-200c & tgt cag gca acc gta ttc acc gtg agt ggt cca tca & \\
\hline short-let-7a-rev & cgt cag atg tcc gag tag agg ggg aac ggc gtg agg tag tag gtt gta ta & 56 \\
\hline short-let-7b-rev & cgt cag atg tcc gag tag agg ggg aac ggc gtg agg tag tag gtt gtg tg & 56 \\
\hline short-let-7c-rev & cgt cag atg tcc gag tag agg ggg aac ggc gtg agg tag tag gtt gta tg & 56 \\
\hline short-miR-I6-rev & cgt cag atg tcc gag tag agg ggg aac ggc gta gca gca cgt aaa ta & 59 \\
\hline short-miR-2 I-rev & cgt cag atg tcc gag tag agg ggg aac ggc gta gct tat cag act ga & 59 \\
\hline short-miR-23b-rev & cgt cag atg tcc gag tag agg ggg aac ggc gat cac att gcc agg g & 58 \\
\hline short-miR-27a-rev & cgt cag atg tcc gag tag agg ggg aac ggc gtt cac agt ggc taa $\mathbf{g}$ & 57 \\
\hline short-miR-I 4 I-rev & cgt cag atg tcc gag tag agg ggg aac ggc gta aca ctg tct ggt aaa g & 56 \\
\hline short-miR-I 45-rev & cgt cag atg tcc gag tag agg ggg aac ggc ggt cca gtt ttc cca gga a & 60 \\
\hline short-miR-200c-rev & cgt cag atg tcc gag tag agg ggg aac ggc gta ata ctg ccg ggt aa & 59 \\
\hline $5 S$ rRNA fw & gcc cga tct cgt ctg atc t & 60 \\
\hline $5 S$ rRNA rev & agc cta cag cac ccg gta tt & \\
\hline$M P-f w$ & tgt cag gca acc gta ttc acc & \\
\hline MP-rev & cgt cag atg tcc gag tag agg & \\
\hline
\end{tabular}



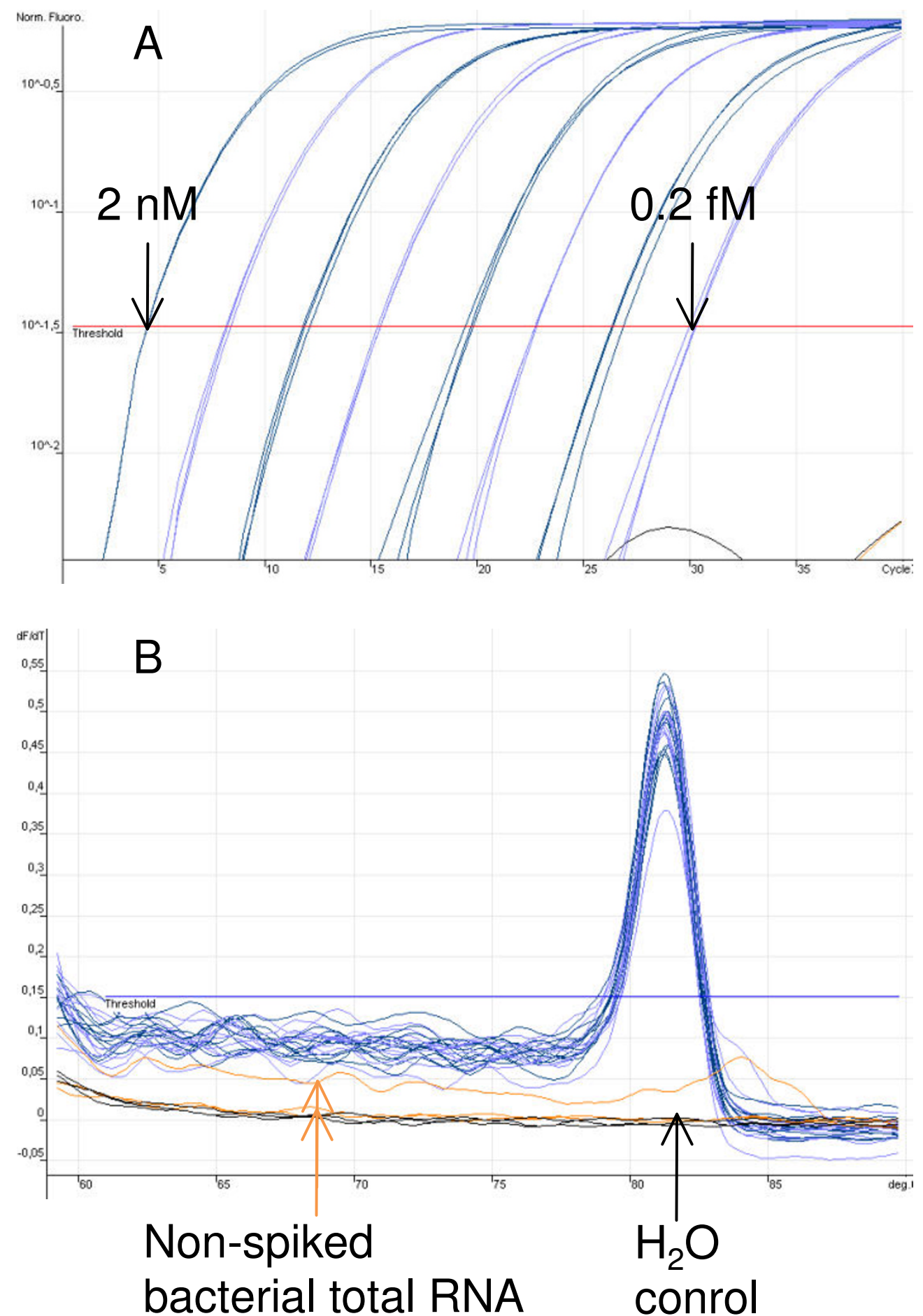

Figure 2

Amplification plot and melting curve of the proposed miR- 45 miR-Q assay. A) Amplification plot of synthetic miRI 45 with $50 \mathrm{ng}$ bacterial total RNA present as complex background. Target input ranged between $2 \mathrm{nM}$ and $0.2 \mathrm{fM}$ in a miR-Q reaction. B) SYBR green melting curve of the miR-I 45 assay. Neither the non-spiked bacterial total RNA control, nor $\mathrm{H}_{2} \mathrm{O}$ control showed a background signal over 40 cycles. 

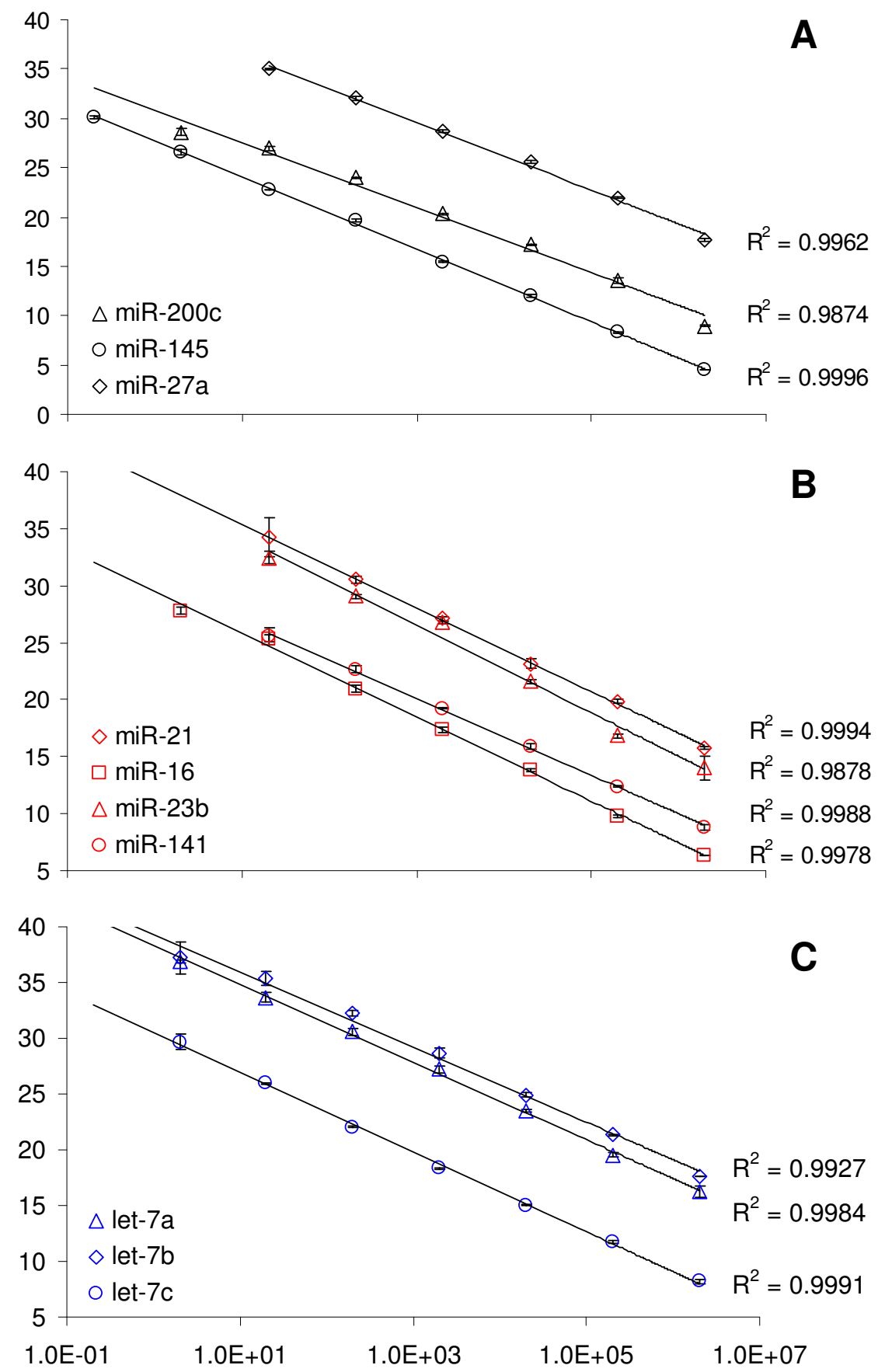

miRNA concentration [fM]

\section{Figure 3}

Dynamic range and sensitivity limit of ten miR-Q assays. Each value represents the mean ( \pm SD) of three measurements. They showed dynamic ranges between 6 and 8 orders of magnitude, comprising a sensitivity of up to $0.2 \mathrm{fM}$ synthetic miRNA. A) Dynamic ranges of miR-Q assays: miR-200c (black triangles), miR-I 45 (black circles), and miR-27a (black rhombi). B) Dynamic ranges of miR-Q assays: miR-2I (red rhombi), miR-I6 (red squares), miR-23b (red triangles), and miR-I4I (red circles). C) Dynamic ranges of miR-Q assays: let-7a (blue triangles), let-7b (blue rhombi), and let-7c (blue circles). 
and let-7c) showed linearities over 7 orders of magnitude, detecting as low as $2 \mathrm{fM}$ synthetic miRNA. Four of the analysed assays (miR-27a, miR-21, miR23b, and miR-141) showed a dynamic range of 6 logs, while at least $20 \mathrm{fM}$ synthetic miRNA in a miR-Q reaction were measured. All of the calculated coefficients of determination $\left(\mathrm{R}^{2}\right)$ ranged between 0.9874 and 0.9996, which underlined the eminent linearity between $\mathrm{Ct}$ values and miRNA input (Figure $3)$. Negative controls were established for all of the ten studied assays by performing RT reactions with nonspiked bacterial total RNA. All studied miR-Q negative control assays gave neither a detectable, nor specific signal over 40 cycles.

\section{Assay specificity and cross reaction between let-7 family members}

The discriminative power and specificity of the miR-Q approach were analysed for three closely sequence-related members of the let-7 family (let-7a, let-7b, and let-7c), which differed only in one or two nucleotides (Table 1). Each synthetic miRNA molecule was applied to each specific assay and the cross reaction of an assay was determined at different miRNA concentrations by offering unspecific miRNA targets. All experiments were performed along the entire dynamic range of assays ( $2 \mathrm{nM}-$ $2 \mathrm{fM}$ in a miR-Q reaction). Absolute quantification of assay-unspecific targets was performed using a calibration curve established with specific targets. The percentage of cross reaction values was calculated between assay-specific and unspecific miRNA targets, while the concentration of assay-specific molecules represented the full value. The miR-Q approach showed a high capability to discriminate between miRNA molecules, which differ by less than two nucleotides. Marginal cross reaction was only observed at miRNA concentrations higher than $200 \mathrm{fM}$ synthetic miRNA in a miR-Q assay with minute values ranging from $0 \%$ to $0.37 \%$, indicating the high specificity and selectivity of each let-7 assay (Table 2). For miRNA concentrations below $200 \mathrm{fM}$, only the assay-specific miRNA was detected. The highest cross reaction values $(0.37 \%)$ were observed using the let-7a assay and synthetic let-7c at high concentrations. No cross reaction at all was detected using the let-7a assay versus let-7b as a target.

\section{Comparison of the miR-Q approach with a commercial qRT-PCR detection kit}

Currently, few commercial miRNA qRT-PCR assays are available. The mirVana ${ }^{\mathrm{TM}}$ qRT-PCR miRNA Detection Kit for let-7b (Ambion) has been applied to validate the performance of the miR-Q assay. The selected commercial assay is well suited for this purpose, since it is also based on an initial RT reaction, followed by SYBR Green quantification. Since our let-7b assay offered a characteristic medium linearity ( 7 orders of magnitude), we decided to
Table 2: Cross reaction of the miR-Q let-7 assays at different target concentrations. The percentage of cross reaction values was calculated between assay-specific and unspecific miRNA targets, while concentration of assay-specific molecules represented the full value.

\begin{tabular}{lccc}
\hline & let-7a miR-Q & let-7b miR-Q & let-7c miR-Q \\
\hline 2 nM let-7a & 100 & 0.31 & 0.01 \\
2 nM let-7b & 0.00 & 100 & 0.23 \\
2 nM let-7c & 0.37 & 0.29 & 100 \\
200 pM let-7a & 100 & 0.31 & 0.01 \\
200 pM let-7b & 0.00 & 100 & 0.13 \\
200 pM let-7c & 0.24 & 0.24 & 100 \\
20 pM let-7a & 100 & 0.30 & 0.01 \\
20 pM let-7b & 0.00 & 100 & 0.10 \\
20 pM let-7c & 0.24 & 0.19 & 100 \\
2 pM let-7a & 100 & 0.00 & 0.00 \\
2 pM let-7b & 0.00 & 100 & 0.00 \\
2 pM let-7c & 0.00 & 0.16 & 100 \\
200 fM let-7a & 100 & 0.00 & 0.00 \\
200 fM let-7b & 0.00 & 100 & 0.00 \\
200 fM let-7c & 0.00 & 0.00 & 100 \\
20 fM let-7a & 100 & 0.00 & 0.00 \\
20 fM let-7b & 0.00 & 100 & 0.00 \\
20 fM let-7c & 0.00 & 0.00 & 100 \\
2 fM let-7a & 100 & 0.00 & 0.00 \\
2 fM let-7b & 0.00 & 100 & 0.00 \\
2 fM let-7c & 0.00 & 0.00 & 100 \\
& & &
\end{tabular}

compare the sensitivity and quantitative power of the miR-Q approach with the competitor using let-7b. Both assays were compared, performing reactions according to the manufacturer's protocol, as well as to our new method. For this purpose, $50 \mathrm{ng}$ of bacterial total RNA was spiked with synthetic let-7b to give final concentrations between $10 \mathrm{nM}$ and $10 \mathrm{fM}$ in RT reaction. cDNAs were quantified in subsequent qPCRs, which were similarly carried out, according to both protocols comparing the performace of both methods within the same qPCR run. Regardless of the two different assay conditions, the miR-Q approach provided a higher sensitivity and linearity, characterised by slightly lower $\mathrm{Ct}$ values and a higher dynamic range (Figure 4). While the competitor assay provided linearity over 6 orders of magnitude with a sensitivity limit at $20 \mathrm{fM}$ synthetic let-7b under optimal conditions, as little as $2 \mathrm{fM}$ synthetic let-7b was detected using the miR-Q assay (Figure 4). Both assays showed excellent amplification efficiencies, ranging between 0.95 and 0.98 and $\mathrm{R}^{2}>0.996$.

Additionally, human total RNA samples from the cell lines A549, HeLa, and HT-29 were employed to validate the performance of the miR-Q assay in real human samples. For this purpose total RNA samples $(50 \mathrm{ng} / \mu \mathrm{l})$ were either spiked with $100 \mathrm{pM}$ synthetic let-7b (spike-in controls) or remained non-spiked (samples). RT reactions were performed with $50 \mathrm{ng}$, $25 \mathrm{ng}$, and $5 \mathrm{ng}$ of all RNA 


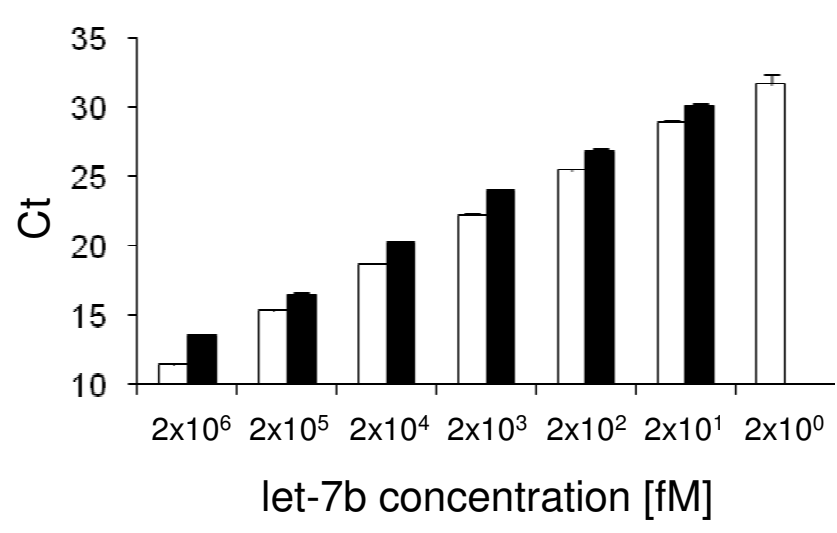

Figure 4

Detection and quantification of synthetic let-7b in the presence of a complex background using the miR-Q assay and mirVana ${ }^{T M}$ qRT-PCR Detection Kit within the same $q P C R$ run according to the mirVana protocol. The purchasable let-7b assay showed a sensitivity limit of $20 \mathrm{fM}$ synthetic let-7b (black columns), while the sensitivity limit of the miR-Q assay turned out to be $2 \mathrm{fM}$ synthetic let-7b (white columns). Each column represents the mean $( \pm S D)$ of three measurements.

samples. The specificity was validated performing side-byside quantification of let-7b using the miR-Q assay as well as the mirVana ${ }^{\mathrm{TM}}$ qRT-PCR miRNA Detection Kit. As shown in Figure 5, let-7b was detected both in spike-in controls and in non-spiked samples using both assays. Both methods revealed consistent high natural let-7b expression in HT-29 cells compared with the other analysed cell lines (Figure 5). It has to be taken into account that the comparative quantification of let-7b by means of the two methods was carried out in two independent qPCR runs. Due to differences between separate qPCR runs, comparative analysis of both methods was performed by calculation of ratios between spike-in controls and non-spiked samples. Both assays exhibited consistent linearity between the spike-in controls and the nonspiked samples demonstrated by the calculated ratio. For example, the miR-Q ratios at different HT-29 RNA concentrations averaged $4.3 \pm 0.3$ (Figure $5 \mathrm{~A}$ ) and the side-byside quantification using the mirVana assay resulted in a mean ratio of $3.0 \pm 0.2$ (Figure $5 \mathrm{~B}$ ).

\section{Expression of miR-I45 and miR-2I in porcine intestinal samples}

In order to test for a demanding practical application, aside from an experimental validation of the assays, the miR-Q approach was used to study differential miRNA expression in biological samples. Therefore, the miR-Q approach was introduced to generate miRNA expression profiles of different porcine intestinal tissues. Target quan- tity was determined by absolute quantification [12], using a calibration curve established by reverse transcription of serially diluted amounts of the particular synthetic miRNA in the presence of $50 \mathrm{ng}$ bacterial total RNA. The expression profiles of two selected miRNAs (miR-145 and miR-21) were exemplified in 50 ng porcine total RNA isolated from the jejunum or ileum of ten piglets by means of the corresponding miR-Q assays (Figure 6). After measuring 5S ribosomal RNA (rRNA) expression as a housekeeping gene, miRNA data were normalised by calculating the ratios of miRNA and 5S rRNA expression values. The expression of 5S rRNA in porcine jejunum and ileum showed low variation among the ten analysed subjects and turned out to be a reliable housekeeping gene for the normalisation of miRNA values (data not shown). The inter-assay variation of 5S rRNA gene expression among the ten analysed samples was determined as a coefficient of variation (CV) in percent [21]. The calculated $\mathrm{CV}$ for the ten ileal samples were $32 \%$ and $21 \%$ for the jejunal samples, respectively.

Expression of miR-145 and miR-21 in analysed samples was first evaluated by performing initial miRNA-Microarray experiments (data not shown). Subsequent miR-Q analysis demonstrated that both miR-145 and miR-21 were differentially expressed in the jejunal and ileal samples of all ten piglets (Figure 6). There was an obvious individual variance in expression of both miRNAs among the studied subjects. However, miR-145 expression levels in the two different intestinal loci showed similar tendencies. As shown in Figure 6A and 6B, animal f exhibited the highest miR-145 expression among the ten samples, both in jejunum and ileum. Interestingly, both intestinal loci of this animal featured the same miR-145:5S rRNA value, which was twice as high as the lowest expression ratios among the group.

Differential miR-21 expression was also observed among jejunal or ileal samples, respectively. However, there was no distinct concordance of miR-21 expression in the two intestinal loci compared with miR-145 expression. The highest miR-21:5S rRNA expression ratios within the ileal samples were about 2.5 times higher compared with the lowest values, while the highest expression value among the jejunal samples turned out to be 3.5 times higher (Figure 6C and 6D).

Expression values of miR-21 were enhanced in both the ileum and jejunum of all analysed animals compared with miR-145. In ileal samples, a 30-fold higher miR-21 expression value was measured compared with miR-145, while the average values in jejunum were enhanced 40fold. 

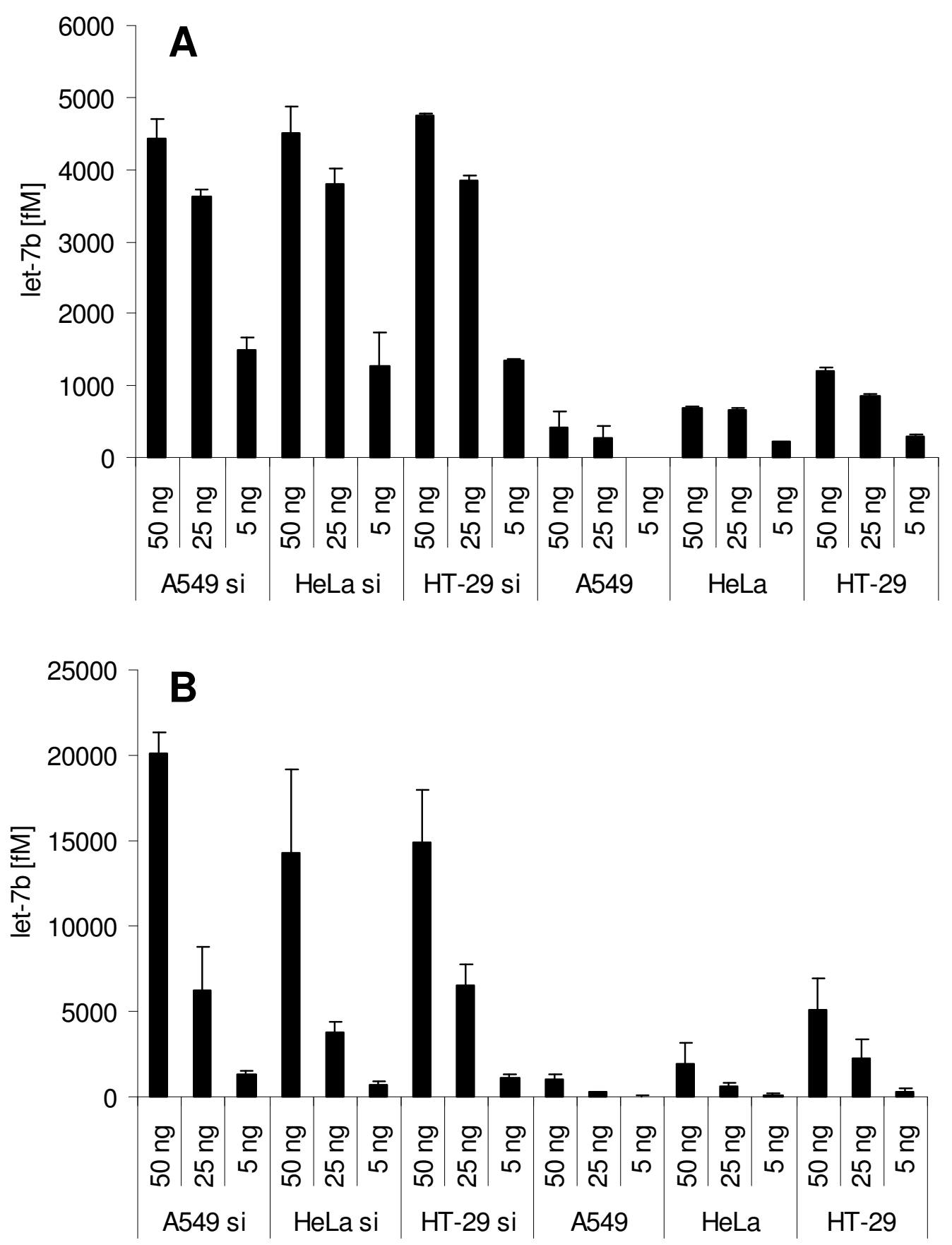

Figure 5

Side-by-side quantification of let-7b in human total RNA samples isolated from the cell lines: A549, HeLa, and HT-29 in two independent qPCR runs. Experiments were performed using the miR-Q approach as well as the mirVana ${ }^{T M}$ qRT-PCR Detection Kit. For this purpose, total RNA samples $(50 \mathrm{ng} / \mu \mathrm{l})$ were either spiked with $100 \mathrm{pM}$ synthetic let-7b (A549 si, HeLa si, and HT-29 si) or remained non-spiked (A549, HeLa, and HT-29). RT reactions were performed with 50 ng, $25 \mathrm{ng}$, and $5 \mathrm{ng}$ of all RNA samples, followed by qPCR detection of let-7b in different runs. Columns represent the mean $( \pm$ $\mathrm{SD}$ ) of three measurements. A) let-7b quantification by means of the miR-Q approach using both the spike-in controls and the non-spiked samples. B) Quantification of let-7b by means of mirVana ${ }^{T M}$ qRT-PCR using both the spike-in controls and the nonspiked samples. 

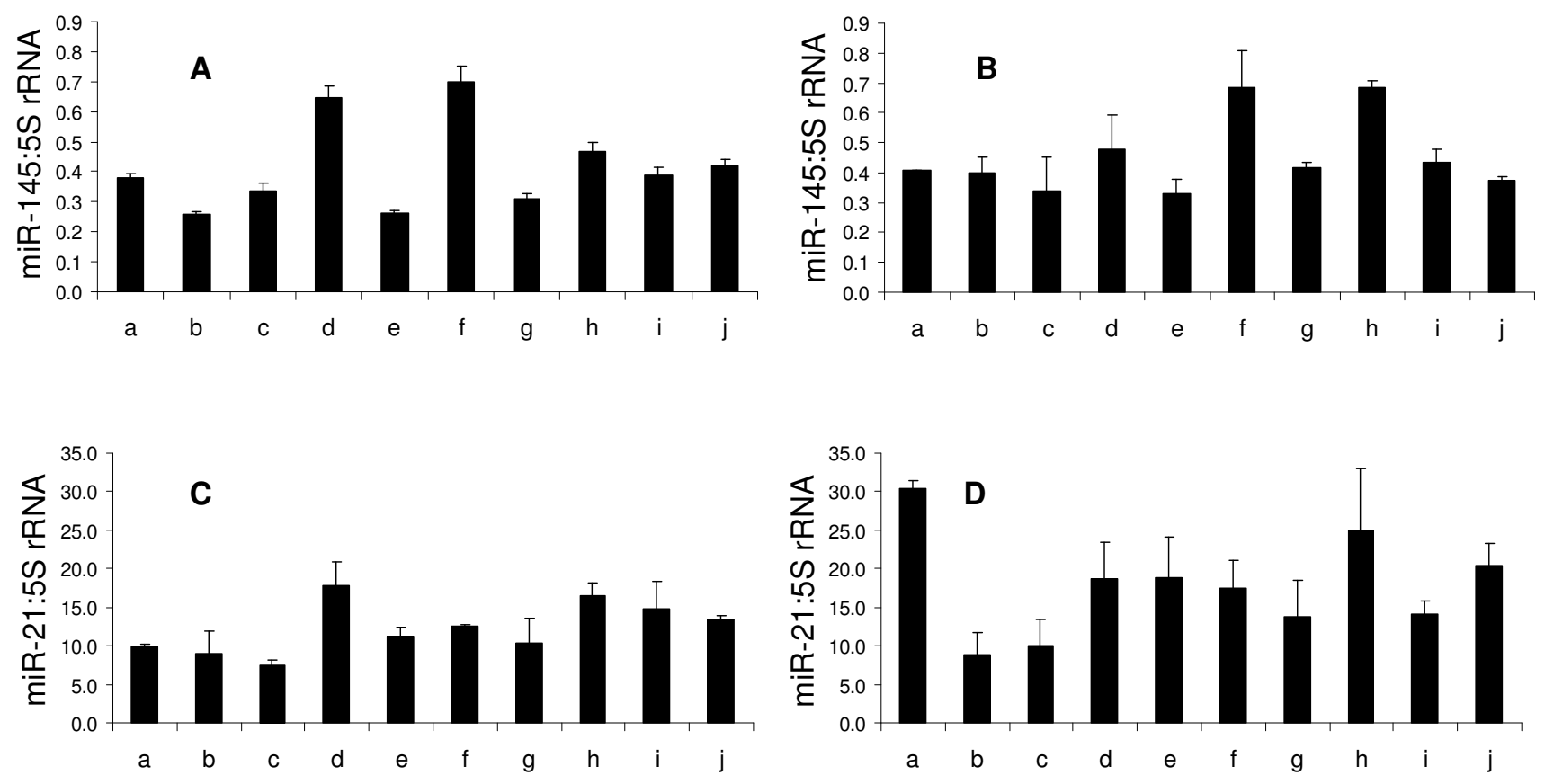

Figure 6

Expression of miR-I45 and miR-2I in porcine intestinal samples. MiRNA expression values were normalised with relating $5 \mathrm{~S}$ rRNA expression data and are given as ratios of expression. Each column represents the mean ( \pm SD) of three measurements. A) Expression of miR-I45 in ileal samples from ten 31 -day-old piglets. B) Expression of miR-I45 in jejunal samples from ten 3I-day-old piglets. C) Expression of miR-2I in ileal samples from ten 3I-day-old piglets. D) Expression of miR-2 I in jejunal samples from ten $3 \mathrm{I}$-day-old piglets.

\section{Discussion}

The expression of various protein coding genes, their role in development or disease, and their regulation become more and more deciphered. Recently, the small non-coding miRNAs have been highlighted as major modulators of eukaryotic gene expression. It is suggested that up to $30 \%$ of human genes may be under the control of miRNAs [22]. MiRNAs are involved in essential developmental processes such as timing, embryogenesis, organogenesis, growth control, and programmed cell death; but they also play a role in human disease, in particular cancer [23]. An increasing number of studies describe aberrant miRNA expression in cancerous tissue. For example, miR-21 was reported as being highly overexpressed in human glioblastoma tumour tissue [24] and in breast tumours, pointing to its function as an oncogene [25]. Other miRNAs such as miR-143 or miR-145 are downregulated in colon carcinomas [26] or in human breast cancer [27]. In many cases, detection of miRNAs and comparative miRNA expression analysis are performed using methods based on probe hybridisation, lacking any amplification step (Northern blot and Microarray). Despite these methods being well established, they are rather limited regarding sensitivity and accurate quan- tification. Otherwise, due to its high level of sensitivity, accuracy, and practical ease, qRT-PCR is accepted as being a powerful technique in comparative expression analysis in life sciences and medicine [28]. In consideration of the aforementioned facts, quantification of miRNA expression by real-time PCR (e.g. as a diagnostic tool in cancer research) is the method of choice. However, few qRT-PCR approaches are adapted to small-sized miRNAs [18,24] and are currently made available by companies. Our miR$\mathrm{Q}$ approach represents a new, alternative method, which exhibits advanced discriminative power and sensitivity. It is based on primer extension, followed by amplification and quantification of the corresponding cDNA, based on the SYBR Green intercalating chemistry. To establish a novel PCR approach for RNA molecules (<30 nt) such as miRNAs, three different oligonucleotides were simultaneously employed, one miRNA-specific molecule (shortmiR-x-rev) for the detection of the corresponding cDNA and two universal primers for the exponential amplification of the product.

We established the described 10 miR-Q assays by randomly choosing miRNAs of interest. Since all of the validated assays proved to be highly sensitive and specific and 
because of the nature of the overhang sequences, we conclude that these sequence parts can be utilised for ubiquitous detection of small RNA molecule. The linearity and sensitivity of the proposed approach apparently correlates with the length of the detected miRNA molecule. According to miRBase sequence data [20], miR-145 has an extended length of $24 \mathrm{nt}$, displaying the longest molecule among the miRNAs in this study. Consequently, the most sensitive assay among the validated ten assays (linearity over 8 orders of magnitude) turned out to be the miR-145 assay, featuring an advanced sensitivity limit. Moreover, most of the analysed miRNA molecules with a length of 22 nt exhibited enhanced assay linearity, compared with shorter molecules. Currently, 475 human miRNAs are published in miRBase (Release 9.2). Based on these data, $67 \%$ of known human miRNAs are at least $22 \mathrm{nt}$ in length. Accordingly, it can be suggested that the general detection limit of the miR-Q approach would be about $1 \mathrm{fM}$ miRNA. This value may even be underestimated, since $27 \%$ of known human miRNAs are longer than $22 \mathrm{nt}$. Different tissues or cell types may contain diverse amounts of RNA. But according to our calculations, a general detection limit of $2 \mathrm{fM}$ correlates with less than 5 measured copies of miRNA molecules per cell. Hence, the proposed approach offers a cost-effective alternative, exhibiting improved sensitivity and specificity compared with other existing methods without using fluorochromic hybridisation probes or LNA-modified oligonucleotides $[18,19]$. Recently, qRT-PCR protocols for profiling of mature miRNAs have been introduced where the entire miRNA population contained in samples is reverse transcribed at the same time (Invitrogen or Qiagen). The application of specific RT primers, however, provides an increased specificity of the assays and reduces cross reaction between closely related miRNA molecules. The gain of higher sensitivity over existing assays is also underlined by comparison of our let-7b assay with a purchasable kit. While the mirVana $^{\mathrm{TM}}$ qRT-PCR miRNA Detection Kit for let-7b provided lower detection limit, the miR-Q let-7b assay turned out to possess an enhanced dynamic range. Furthermore, the miR-Q assay turned out to be highly discriminative, exhibiting almost no cross reaction between related miRNA molecules, which differed by at least one base. As shown in the let-7a assay versus let-7b as a target, the optimisation of the approach's discriminative power can be achieved by positioning the terminal 3 ' nucleotide of short-miR-x-rev at one of the mismatched bases. Since in real human samples the RNA species are much richer, we performed side-by-side quantification of let-7b in different human cell lines using miR-Q and mirVana ${ }^{\mathrm{TM}}$ qRT-PCR and comparing the outcomes of the different assays. The miR-Q results such as the ratios between the spike-in controls and the non-spiked samples were verified using the commercial kit, pointing to the specificity of the miR-Q assay to detect mature miRNA molecules.
To minimise possible sample-to-sample variation due to imbalanced initial total RNA input, we chose 5S rRNA to normalise miRNA expression. Based on the small size of $5 S$ rRNA (representing the small RNA fraction in total RNA samples) and its high conservation level among various species, it appears to be an appropriate gene for the normalisation of miRNAs. Vandesompele et al. [21] studied the normalisation of qRT-PCR data by geometric means. Depending on the selected genes, tissues, and samples, they reported average $\mathrm{CV}$ values ranging from $15 \%$ to $50 \%$. Despite the fact that we only used the $5 \mathrm{~S}$ rRNA expression values and not a geometric mean, our calculated $\mathrm{CV}$ values correlate well with their data for pooled tissues. Intestinal RNA samples used in this study also represent a complex starting material, since the total RNA was isolated from whole tissues.

miR-21 was reported as being overexpressed in various human cancerous tissues, including colon carcinoma $[29,30]$ and represents an antiapoptotic factor [30]. While common miRNA dysregulation in cancer seems to result in a gain of expression [29], some miRNAs such as miR145 are downregulated in colorectal carcinomas $[26,30]$. Dysregulation of these miRNAs in human colorectal cancer points to their potential role in cell proliferation and differentiation in intestinal tissues. Variation in porcine miRNA expression among the ten examined piglets may therefore reflect the individual differences in the intestinal development of the animals. The measured miR-145 and miR-21 expression values in porcine intestinal samples should basically rely on detection of mature miRNA molecules. Within this context, Northern blot analysis and qRT-PCR studies have already shown that the cellular steady-state level of miRNA precursors is negligible, compared with the mature miRNA $[17,18]$.

\section{Conclusion}

Despite the existence of commercial miRNA qRT-PCR approaches, there is an increasing need for fast, reliable, and cost-effective assays, which are adaptable for any research group interested in miRNA detection. Our miR-Q approach provides a linearity of up to 8 orders of magnitude detecting as low as $0.2 \mathrm{fM}$ miRNA molecules.

It offers an alternative method for scientists interested in detecting and quantifying miRNA expression in total RNA samples from different species and tissues.

\section{Methods \\ Oligonucleotides and synthetic miRNA molecules}

Ten known miRNA molecules were chosen, inter alia, according to preliminary miRNA-Microarray screening experiments using porcine intestinal samples. These miRNA sequences were chosen from the miRBase Sequence database Release 9.2 [20] and oligonucleotides 
were designed for every assay (Table 1). Synthetic miRNA molecules were used for the validation of assays. All DNAand RNA-oligonucleotides were synthesised by Metabion AG (Martinsried, Germany).

\section{Total RNA isolation from samples}

Human total RNA from the cervical carcinoma cell line HeLa (ATCC No.: CCL-2), the colon carcinoma cells HT29 (ATCC No.: HTB-38), and the lung carcinoma cell line A549 (ATCC No.: CCL-185) as well as porcine total RNA from intestinal tissues were prepared using the mirVana miRNA Isolation Kit (Ambion, Darmstadt, Germany), according to the manufacturer's protocol. The porcine intestinal samples included the jejunum and ileum of ten 31-day-old piglets (EUROC $\times$ Pietrain).

In order to validate the new assays, bacterial total RNA was employed as an unspecific complex RNA background in reverse transcription (RT) reactions. RNA was isolated from Escherichia coli DH5á using the Invisorb Spin Cell RNA Mini Kit (Invitek, Berlin, Germany), according to the manufacturer's protocol.

The RNA quality and quantity of all samples were proven using the Agilent 2100 Bioanalyzer and the RNA Nano Chips (Agilent, Waldbronn, Germany).

\section{Reverse transcription}

The validation of every assay was performed by RT of certain amounts of the corresponding synthetic miRNA with 50 ng bacterial total RNA present, representing a complex RNA background. Furthermore, the human total RNA as well as the porcine intestinal total RNA were used for reverse transcription.

$250 \mathrm{fmol}$ of the miRNA-specific DNA-oligonucleotide $(R T 6-m i R-x)$ with $5^{\prime}$ overhang and the RevertAid ${ }^{\mathrm{TM}} \mathrm{M}$ MuLV Reverse Transcriptase (Fermentas GmbH, St. LeonRoth, Germany) were employed to transcribe miRNA into cDNA. A mixture of $50 \mathrm{ng}$ human or porcine total RNA or bacterial total RNA spiked with synthetic miRNA and RT6$m i R-x$ was first prepared in a $4 \mu$ l volume. The mixture was incubated at $70^{\circ} \mathrm{C}$ for $5 \mathrm{~min}$ and chilled on ice. Then, the volume was brought up to $10 \mu \mathrm{l}$ by adding the RT-Buffer, $1 \mathrm{mM}$ dNTPs, $100 \mathrm{U}$ Reverse Transcriptase and water. The reaction was incubated at $37^{\circ} \mathrm{C}$ for 5 min followed by $42^{\circ} \mathrm{C}$ for $60 \mathrm{~min}$. The enzyme was inactivated by heating at $70^{\circ} \mathrm{C}$ for $10 \mathrm{~min}$. The standard was prepared using 50 ng of bacterial total RNA spiked with different amounts of synthetic miRNA (10 $\mathrm{nM}-1 \mathrm{fM}$ in RT reaction) and was applied for validation and for preparation of QPCR calibration curves. 50 ng of non-spiked bacterial total RNA was used as negative control.

\section{Quantitative PCR}

The optimal annealing temperature $\left(\mathrm{T}_{\text {anopt }}\right)$ for every miR$\mathrm{Q}$ assay was first proven by performing a conventional PCR with an annealing temperature gradient ranging from 53 to $65^{\circ} \mathrm{C}$. The reaction was performed with $4 \mathrm{nM}$ shortmiR-x-rev, $100 \mathrm{nM} \mathrm{MP-fw}$, and $100 \mathrm{nM} \mathrm{MP-rev} \mathrm{using} \mathrm{the}$ Immolase DNA Polymerase (Bioline, Luckenwalde, Germany). The reaction was carried out according to the qPCR conditions (see below) in $25 \mu$ l final volume using $2 \mu \mathrm{l}$ of cDNA, which was obtained from RT reaction with $10 \mathrm{pM}$ of the particular synthetic miRNA. The product size ranged from 82 to $85 \mathrm{bp}$, depending on the miRNA being detected. After the $T_{\text {anopt }}$ was determined, the cDNA was quantified using the Rotor-Gene 3000 real-time Detection System (Corbett Life Science, Sydney, Australia) as well as the StepOnePlus ${ }^{\mathrm{TM}}$ Real-Time PCR System (Applied Biosystems, Darmstadt, Germany). For this purpose, triplicate measurements of $2 \mu \mathrm{l}$ cDNA were made in $10 \mu \mathrm{l}$ final reaction volume. SYBR Green qPCR was performed using the SensiMix DNA Kit (Quantace Ltd., Berlin, Germany), $4 \mathrm{nM}$ short-miR-x-rev, $100 \mathrm{nM} \mathrm{MP-fw}$, and $100 \mathrm{nM} M P$-rev. The amplification was carried out via the first step at $95^{\circ} \mathrm{C}$ for $10 \mathrm{~min}$, followed by 40 cycles with $15 \mathrm{~s}$ at $95^{\circ} \mathrm{C}, 10 \mathrm{~s}$ at the particular annealing temperature (Table 1 ), and 20 s at $72^{\circ} \mathrm{C}$. The fluorescence signal was acquired at $72^{\circ} \mathrm{C}$ and the $\mathrm{Ct}$ values were converted into $\mathrm{fM}$ miRNA, using a miRNA-specific calibration curve. MiRNA amounts were determined by triplicate measurements for each sample, compared with a calibration curve established by reverse transcription of serially diluted amounts of the particular synthetic miRNA in the presence of $50 \mathrm{ng}$ bacterial total RNA. The RT reaction of non-spiked bacterial total RNA samples and no template controls were used as negative controls.

\section{S ribosomal RNA normalisation}

Sample-to-sample variation of miRNA expression in porcine intestinal samples was corrected by normalisation with $5 \mathrm{~S}$ rRNA chosen as a housekeeping gene. Firstly, 50 ng of porcine total RNA was reverse-transcribed using the RevertAid $^{\mathrm{TM}}$ M-MuLV Reverse Transcriptase (Fermentas $\mathrm{GmbH}$ ), according to the manufacturer's protocol using random Hexamers. 5S rRNA molecules were quantitated by triplicate measurements of $2 \mu \mathrm{l}$ cDNA in $10 \mu \mathrm{l}$ final reaction volume. SYBR Green qPCR was performed using the SensiMix DNA Kit (Quantace Ltd.) and $0.2 \mu \mathrm{M}$ of each primer $5 S$ rRNA-fw and $5 S$ rRNA-rev (table 1). Amplification was carried out via the first step at $95^{\circ} \mathrm{C}$ for $10 \mathrm{~min}$, followed by 40 cycles with $15 \mathrm{~s}$ at $95^{\circ} \mathrm{C}, 10 \mathrm{~s}$ at $60^{\circ} \mathrm{C}$ and $20 \mathrm{~s}$ at $72^{\circ} \mathrm{C}$, providing an amplicon of $114 \mathrm{bp}$. The fluorescence signal was acquired at $72^{\circ} \mathrm{C}$ and $\mathrm{Ct}$ values were converted into fg $5 \mathrm{~S}$ rRNA per qPCR reaction using a calibration curve, which was established by serial dilutions of the corresponding PCR product. Normalisation was per- 
formed by calculating the miRNA:5S rRNA expression ratios.

\section{Competing interests}

The authors declare that neither financial nor non-financial competing interests exist. A European patent application (no. 07006897.8 ) is pending.

\section{Authors' contributions}

SST conceived of the study, performed experiments and analyses, wrote and edited the manuscript. BKL and RB performed experiments and analyses. JS collected the porcine intestinal samples and contributed to data analysis. RE contributed to the writing of the manuscript and to the assay design. All authors read and approved the final manuscript.

\section{Acknowledgements}

We are grateful to Patrik Varadinek (Freie Universität Berlin), Dr. Christian Wunsch (ipal GmbH), Dr. Bettina Büttner (ipal GmbH), and Dr. Georg J. Hoppe (Forrester \& Boehmert) for their active support in patent application (European Patent Application No. 07006 897.8). We also would like to thank Dr. Astrid Lewin (Robert Koch-Institut, Berlin) and Dr. Joachim Mankertz (Charité, Campus Benjamin Franklin, Berlin) for providing the cell lines A549 and HT-29, respectively. Furthermore, we would like to thank Andrea Snelling for critical reading of the manuscript.

The study was funded by the "Forschungskommission" of the Freie Universität Berlin (Fonds 02235). Tissue Samples were donated by project DFGEi296/I2-2.

\section{References}

I. Kloosterman WP, Plasterk RH: The diverse functions of microRNAs in animal development and disease. Dev Cell 2006, II:44I-450

2. Hamilton AJ, Baulcombe DC: $\mathbf{A}$ species of small antisense RNA in posttranscriptional gene silencing in plants. Science 1999, 286:950-952.

3. Zhang $B$, Wang $Q$, Pan $X$ : MicroRNAs and their regulatory roles in animals and plants. I Cell Physiol 2007, 2 1 0:279-289.

4. Kim VN, Nam JW: Genomics of microRNA. Trends Genet 2006, 22:165-173.

5. Jackson RJ, Standart N: How do microRNAs regulate gene expression? Sci STKE 2007, 2007:re I.

6. Kim J, Krichevsky A, Grad Y, Hayes GD, Kosik KS, Church GM Ruvkun G: Identification of many microRNAs that copurify with polyribosomes in mammalian neurons. Proc Natl Acad Sci U S A 2004, 101:360-365.

7. Lee RC, Ambros V: An extensive class of small RNAs in Caenorhabditis elegans. Science 200I, 294:862-864.

8. Babak T, Zhang W, Morris Q, Blencowe BJ, Hughes TR: Probing microRNAs with microarrays: tissue specificity and functional inference. Rna 2004, 10:1813-1819.

9. Nelson PT, Baldwin DA, Scearce LM, Oberholtzer JC, Tobias JW Mourelatos Z: Microarray-based, high-throughput gene expression profiling of microRNAs. Nat Methods 2004, I: $|55-16|$

10. Liang RQ, Li W, Li Y, Tan CY, Li JX, Jin YX, Ruan KC: An oligonucleotide microarray for microRNA expression analysis based on labeling RNA with quantum dot and nanogold probe. Nucleic Acids Res 2005, 33:e 17.

II. Neely LA, Patel S, Garver J, Gallo M, Hackett M, McLaughlin S, Nade M, Harris J, Gullans S, Rooke J: A single-molecule method for the quantitation of microRNA gene expression. Nat Methods 2006 3:4l-46.
12. Wong ML, Medrano JF: Real-time PCR for mRNA quantitation. Biotechniques 2005, 39:75-85.

13. Malinen E, Kassinen A, Rinttila T, Palva A: Comparison of realtime PCR with SYBR Green I or 5'-nuclease assays and dotblot hybridization with rDNA-targeted oligonucleotide probes in quantification of selected faecal bacteria. Microbiology 2003, I 49:269-277.

14. Palmer S, Wiegand AP, Maldarelli F, Bazmi H, Mican JM, Polis M, Dewar RL, Planta A, Liu S, Metcalf JA, Mellors JW, Coffin JM: New real-time reverse transcriptase-initiated $P C R$ assay with single-copy sensitivity for human immunodeficiency virus type I RNA in plasma. I Clin Microbiol 2003, 41:453 I-4536.

15. Schmittgen TD, Jiang J, Liu Q, Yang L: A high-throughput method to monitor the expression of microRNA precursors. Nucleic Acids Res 2004, 32:e43.

16. Jiang J, Lee EJ, Gusev Y, Schmittgen TD: Real-time expression profiling of microRNA precursors in human cancer cell lines. Nucleic Acids Res 2005, 33:5394-5403.

17. Lagos-Quintana M, Rauhut R, Yalcin A, Meyer J, Lendeckel W, Tuschl $\mathrm{T}$ : Identification of tissue-specific microRNAs from mouse. Curr Biol 2002, I 2:735-739.

18. Raymond CK, Roberts BS, Garrett-Engele P, Lim LP, Johnson JM: Simple, quantitative primer-extension PCR assay for direct monitoring of microRNAs and short-interfering RNAs. Rna 2005, II:1737-1744.

19. Chen C, Ridzon DA, Broomer AJ, Zhou Z, Lee DH, Nguyen JT, Barbisin M, Xu NL, Mahuvakar VR, Andersen MR, Lao KQ, Livak KJ, Guegler KJ: Real-time quantification of microRNAs by stem-loop RT-PCR. Nucleic Acids Res 2005, 33:el 79.

20. Griffiths-Jones S, Grocock RJ, van Dongen S, Bateman A, Enright AJ: miRBase: microRNA sequences, targets and gene nomenclature. Nucleic Acids Res 2006, 34:D 140-4.

21. Vandesompele J, De Preter K, Pattyn F, Poppe B, Van Roy N, De Paepe A, Speleman F: Accurate normalization of real-time quantitative RT-PCR data by geometric averaging of multiple internal control genes. Genome Biol 2002, 3:RESEARCH0034.

22. Lewis BP, Burge CB, Bartel DP: Conserved seed pairing, often flanked by adenosines, indicates that thousands of human genes are microRNA targets. Cell 2005, 120:15-20

23. Alvarez-Garcia I, Miska EA: MicroRNA functions in animal development and human disease. Development 2005, I32:4653-4662.

24. Chan JA, Krichevsky AM, Kosik KS: MicroRNA-2I is an antiapoptotic factor in human glioblastoma cells. Cancer Res 2005, 65:6029-6033.

25. Si ML, Zhu S, Wu H, Lu Z, Wu F, Mo YY: miR-2I-mediated tumor growth. Oncogene 2007, 26:2799-2803.

26. Michael MZ, SM OC, van Holst Pellekaan NG, Young GP, James RJ: Reduced accumulation of specific microRNAs in colorectal neoplasia. Mol Cancer Res 2003, I:882-89I.

27. lorio MV, Ferracin M, Liu CG, Veronese A, Spizzo R, Sabbioni S, Magri E, Pedriali M, Fabbri M, Campiglio M, Menard S, Palazzo JP, Rosenberg A, Musiani P, Volinia S, Nenci I, Calin GA, Querzoli P, Negrini M, Croce CM: MicroRNA gene expression deregulation in human breast cancer. Cancer Res 2005, 65:7065-7070.

28. Mocellin S, Rossi CR, Pilati P, Nitti D, Marincola FM: Quantitative real-time PCR: a powerful ally in cancer research. Trends Mol Med 2003, 9:189-195.

29. Volinia S, Calin GA, Liu CG, Ambs S, Cimmino A, Petrocca F, Visone R, lorio M, Roldo C, Ferracin M, Prueitt RL, Yanaihara N, Lanza G, Scarpa A, Vecchione A, Negrini M, Harris CC, Croce CM: A microRNA expression signature of human solid tumors defines cancer gene targets. Proc Natl Acad Sci U S A 2006, 103:2257-226I.

30. Bandres E, Cubedo E, Agirre X, Malumbres R, Zarate R, Ramirez N, Abajo A, Navarro A, Moreno I, Monzo M, Garcia-Foncillas J: Identification by Real-time PCR of I 3 mature microRNAs differentially expressed in colorectal cancer and non-tumoral tissues. Mol Cancer 2006, 5:29. 